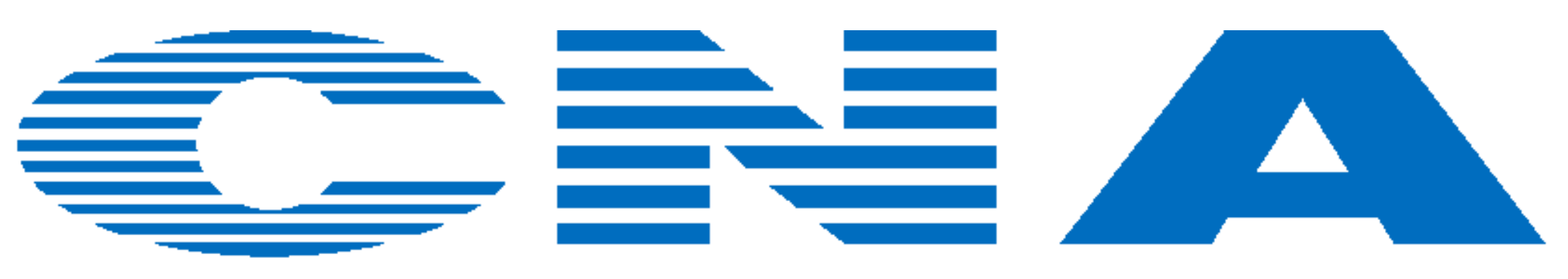

Centro Nacional de Aceleradores (ㄷ)

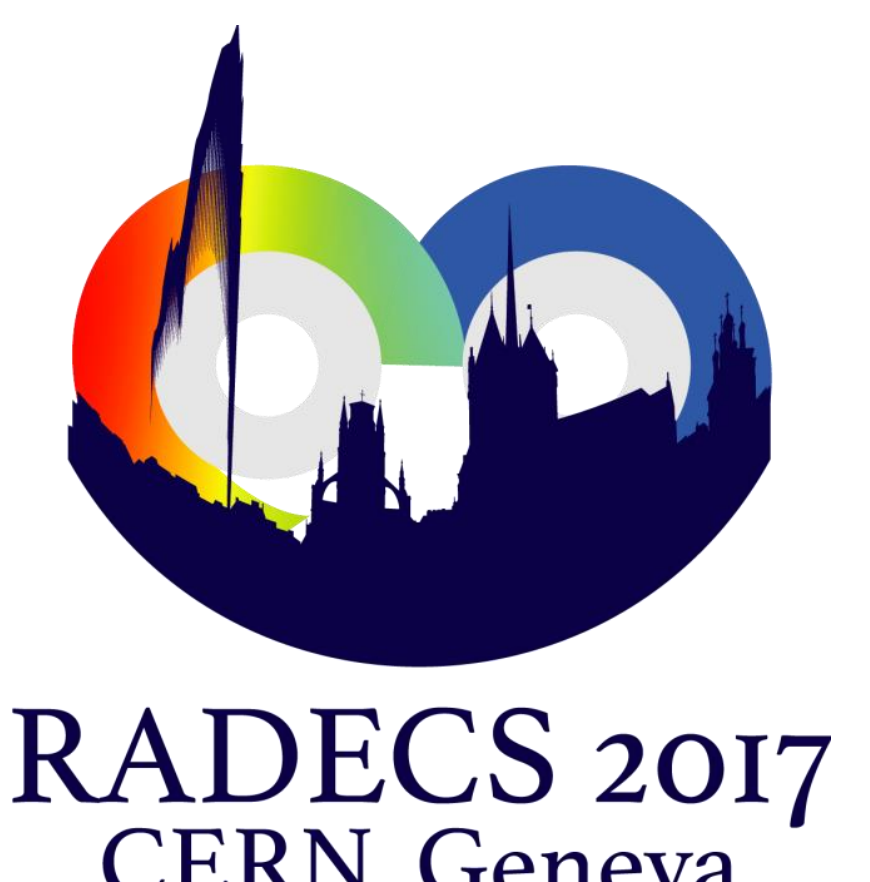

RADECS 2017

\section{ALTER}

T E C H NOLOG Y

\title{
FARMER CHAMBER RESPONSE TO DIFFERENT FILTER BOX AND SURROUNDING CONFIGURATIONS
}

\section{- ARE BEING PERFORMED THE TID TESTS PROPERLY? -}

Pedro Martín-Holgado¹ (pedromartin-ext@us.es), Y. Morilla1(ymorilla@us.es), M. Domínguez² (manuel.dominguez@altertechnology.com), G. Fernández ${ }^{2}$ (gonzalo.fernandez@altertechnology.com)

回紫 1 NATIONAL CENTRE FOR ACCELERATORS Y) C/ Tomás Alba Edison, 7. E-41092, Seville. Spain.
2 ALTER TECHNOLOGY TÜV NORD SAU c/ Tomás Alba Edison, 4. E-41092, Seville. Spain.

The use of a filter box for TID test is a recommendation present in the most relevant test method standards. However, the absence of specific details can produce discrepancies between different radiation facilities and dosimetry procedures.
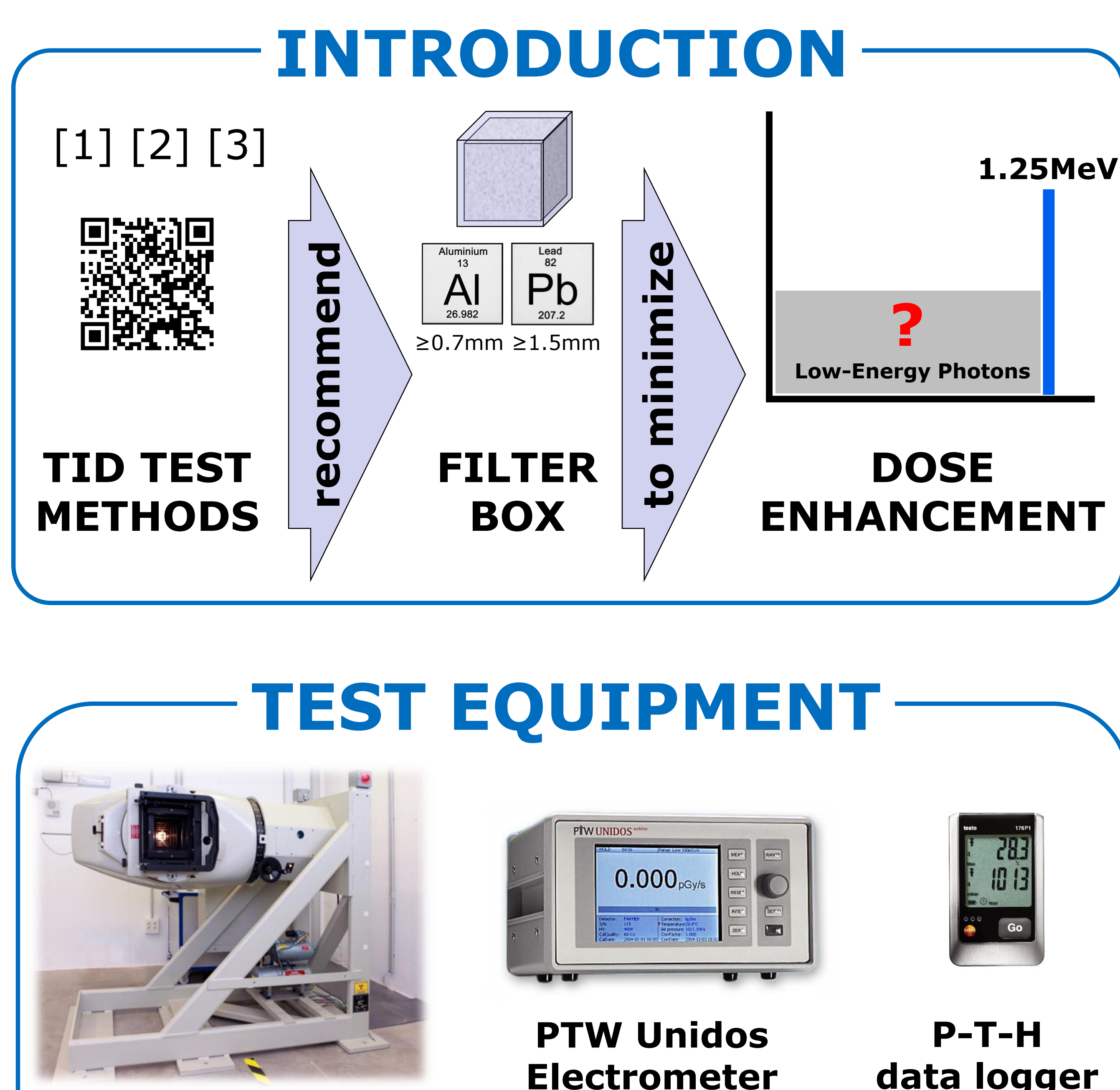

Gamma Irradiator
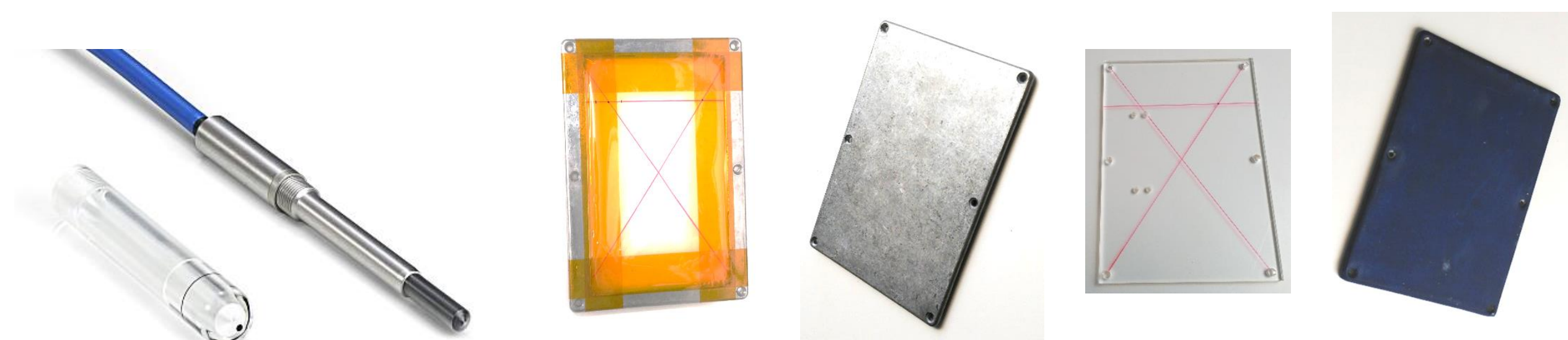

PTW Farmer C1

C2 $\mathrm{C} 3$

Ionization Chamber

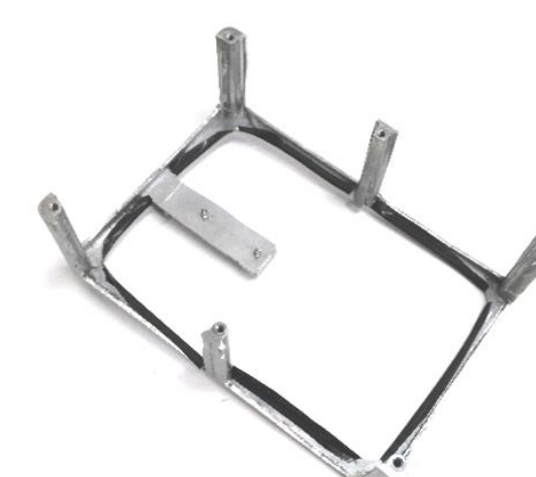

F1

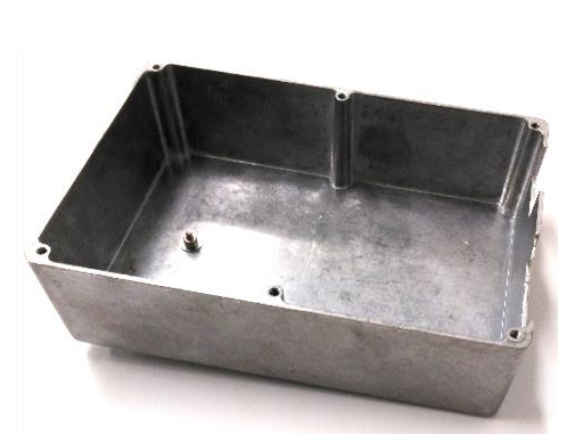

F2 Filter Box Faces

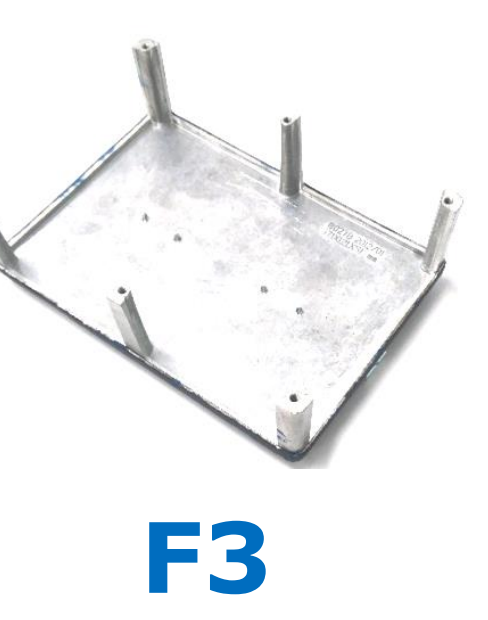
3

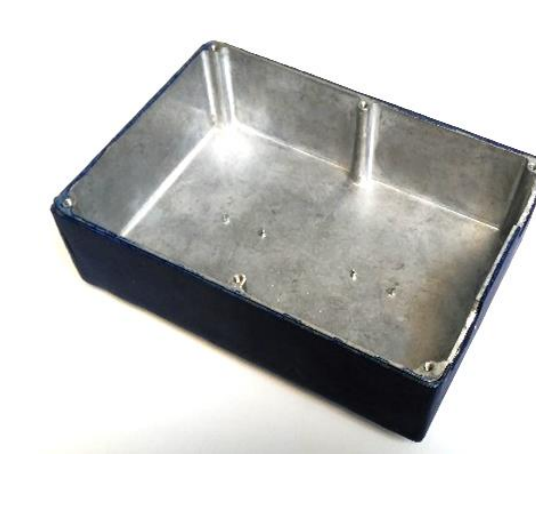

F4

TEST SETUP

Gamma

Irradiator

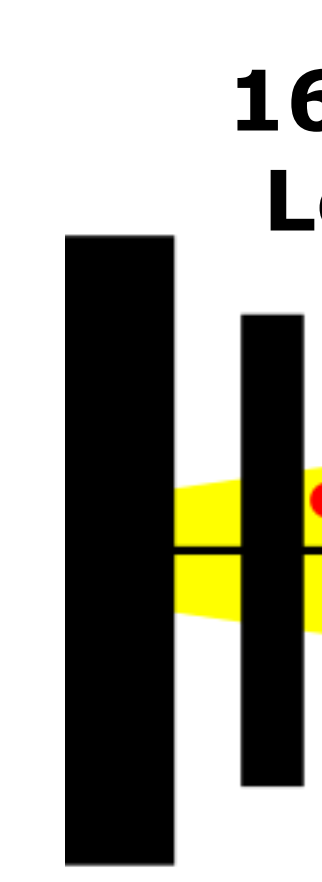

Lead

B4

B1 B3

\section{EXPERIMENTAL RESULTS}

The following spheres represent the dose rate change respect to the reference value in function of the faces of the filter box (orange), the cover of the filter box (yellow), and the boundary conditions (green). The volume of the spheres is directly proportional to the absolute value of the relative dose rate, and the bright halo indicates a negative value.

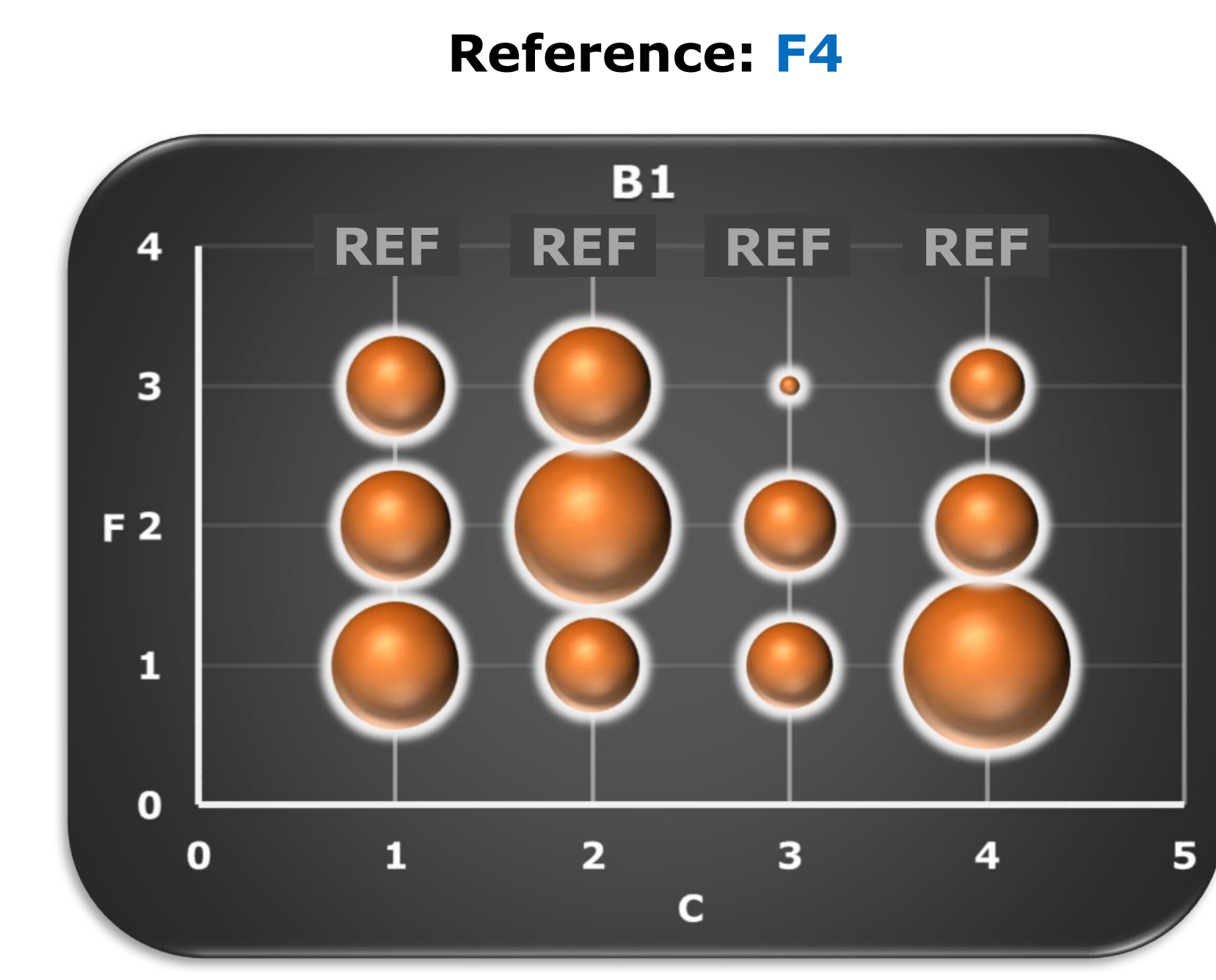

Reference: B1

Reference: C4
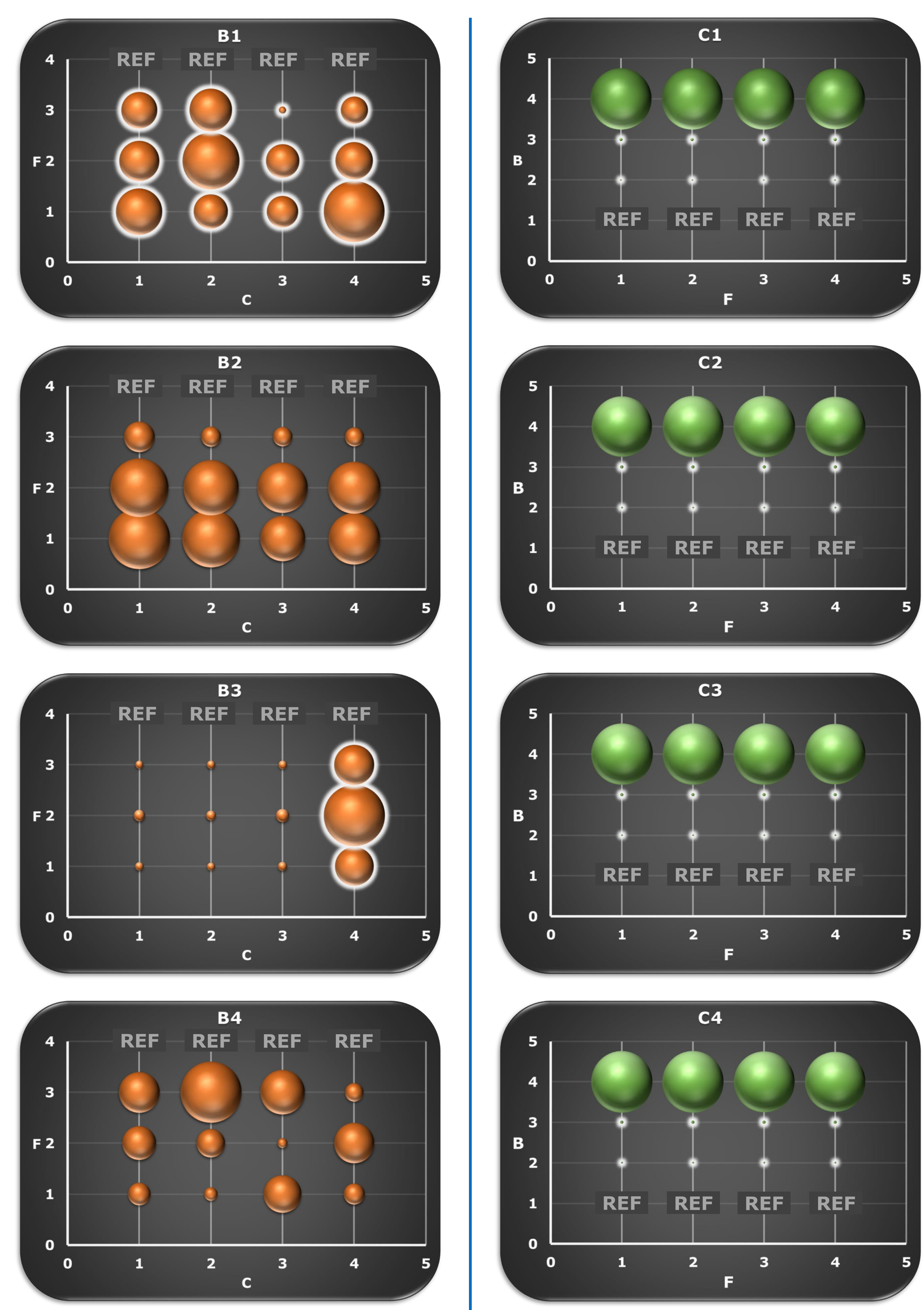

When $B=B 2, F 3$ is closer to $F 4$ (reference) than $F 1$
and $F 2$, probably because the main contribution of ow-energy photons comes from the wall. of faces has no influence. The máximum absolute

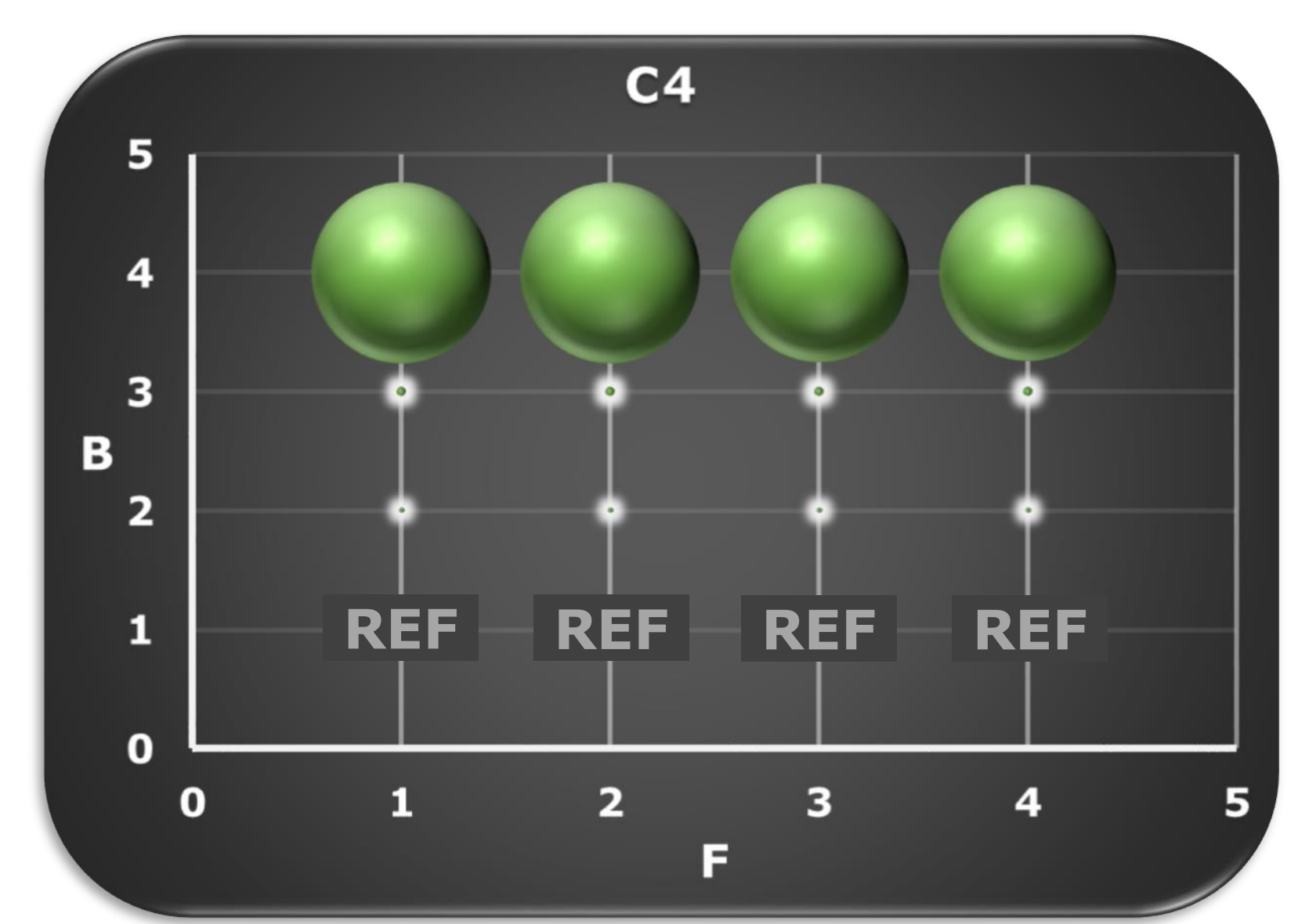

The different dose rates measured at B1-B4 with different $C-F$ parameters bear no relation per se because B1-B4 correspond to different
SDD, but it can be observed that the type of (D) conditions equally (at this facility).
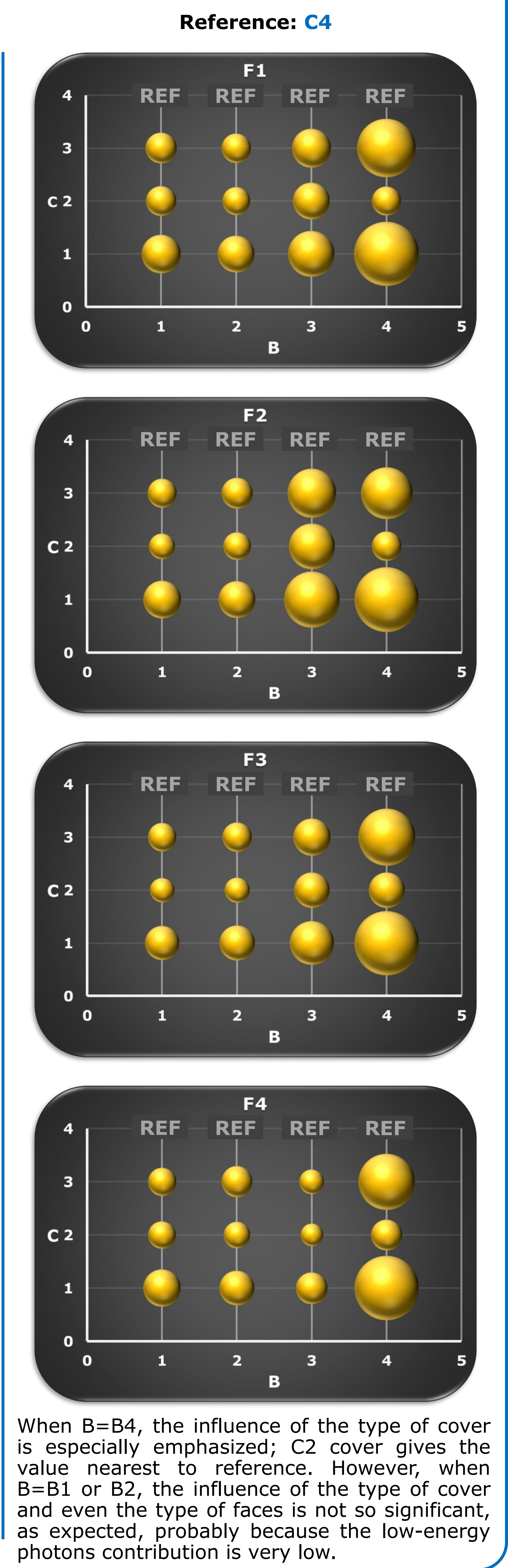

\section{TEST PARAMETERS}

\section{FILTER BOX}

COVER

C1: open

C2: $2 \mathrm{~mm} \mathrm{Al}$

C3: $5 \mathrm{~mm}$ PMMA

C4: $2 \mathrm{~mm} \mathrm{Al}+1.5 \mathrm{~mm} \mathrm{~Pb}$
FILTER BOX

FACES

F1: open 5 sides

F2: Al 5 sides

F3: $\mathrm{Al}+\mathrm{Pb}$ back side

F4: $\mathrm{Al}+\mathrm{Pb} 5$ sides

\section{BOUNDARY} CONDITION

B1: surrounded by free space B2: $20 \mathrm{~cm}$ before concrete wall B3: just before $83 \mathrm{~mm} \mathrm{~Pb}$ B4: just after $16 \mathrm{~mm} \mathrm{~Pb}$

\section{REFERENCES}

\section{[1] Total Dose Steady-State Irradiation Test Method, ESCC Detail Specification 22900, ESA.
[2] Steady-State Total Dose Irradiation Procedure, MLL-STD-750 TM 1019 Test Method Standard for Semiconductor devices, DLA.}

\section{CONCLUSIONS AND FURTHER WORK}

Dose enhancement effects depend strongly of the boundary conditions and the used filter box.

$\square$ This work reveal the needed of including different facilities (source configuration, layout, geometries, etc.) and other dosimetry systems to analyse the influence of these parameters.

- This qualitative analysis leads us to conclude that the generic recommendation of the test methods about the ideal filter box could be improved, considering important parameters of the radiation facilities.

a A deeper dose enhancement factor study is mandatory to understand the physics behind and incorporate practical recommendations in the applicable TID test methods.

- Currently, CNA ${ }^{1}$ ATN2 ${ }^{2}$, ESA (European Space Agency), UML (University of Massachusetts Lowell) and PTW are planning a collaborating and ambitious project to carry out a more complete study about this matter. 